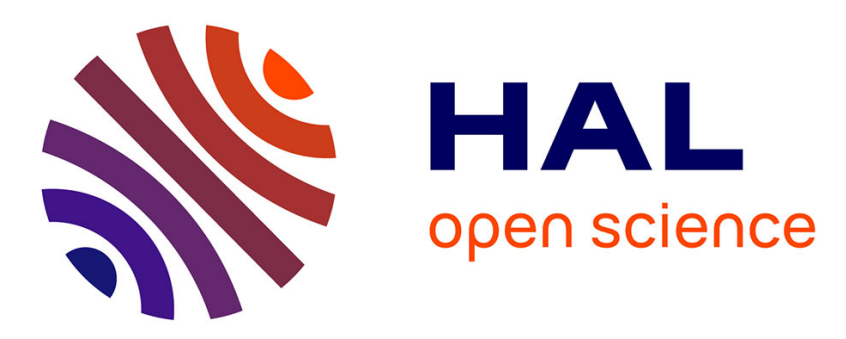

\title{
Gold-catalyzed enantioselective functionalization of indoles
}

Pierre Milcendeau, Nazarii Sabat, Angélique Ferry, Xavier Guinchard

\section{To cite this version:}

Pierre Milcendeau, Nazarii Sabat, Angélique Ferry, Xavier Guinchard. Gold-catalyzed enantioselective functionalization of indoles. Organic \& Biomolecular Chemistry, 2020, 18 (31), pp.6006 - 6017. 10.1039/d0ob01245a . hal-03004194

\section{HAL Id: hal-03004194 https://hal.science/hal-03004194}

Submitted on 26 Nov 2020

HAL is a multi-disciplinary open access archive for the deposit and dissemination of scientific research documents, whether they are published or not. The documents may come from teaching and research institutions in France or abroad, or from public or private research centers.
L'archive ouverte pluridisciplinaire HAL, est destinée au dépôt et à la diffusion de documents scientifiques de niveau recherche, publiés ou non, émanant des établissements d'enseignement et de recherche français ou étrangers, des laboratoires publics ou privés. 


\section{Gold-Catalyzed Enantioselective Functionalizations of Indoles}

Received 00th January 20xx, Accepted 00th January 20xx

DOI: $10.1039 / \times 0 \times x 00000 x$

\author{
Pierre Milcendeau, ${ }^{a, \S}$ Nazarii Sabat, ${ }^{a, \S}$ Angélique Ferry*b,c and Xavier Guinchard*a
}

Gold catalysis and indole chemistry are two mature and prolific fields. The gold-catalyzed functionalization of indoles has produced numerous results and paved the way for novel strategies in the building of molecular complexity. However -and curiously- though enantioselective gold catalysis is now a well-established field, it has been relatively little applied to the modification of indoles. This review exhaustively highlights the enantioselective gold-catalyzed examples of the functionalization of indoles in order to highlight the strengths and limitations of the method.

\section{Introduction}

The indole heterocycle holds a special place in heterocyclic chemistry. Discovered and characterized more than 150 years ago by Baeyer, ${ }^{1}$ the interest in this heterocycle has never decreased, probably because of its prominence in natural products and biologically active compounds. ${ }^{2-8}$ Its reactivity and the rich chemistry developed around the indole ring are also crucial to understand its popularity in the scientific community and all the efforts directed toward its synthesis and functionalization..$^{5-1011}$ Over the past 20 years, the field of homogeneous gold catalysis exploded, resulting in a paradigm shift on the retrosynthetic analyses, especially in the field of carbon-heteroatom bond formation. ${ }^{12-17}$ With a careful work on the ligand design, enantioselective gold catalysis rapidly became possible and efficient -though difficulties linked to the linear geometry of gold complexes and outer-sphere mechanisms are still not fully overcome. ${ }^{18-23}$ Not surprisingly, these two worlds -indole chemistry and gold catalysis- met quickly after chemist's eyes opened on the catalytic abilities of gold complexes in homogeneous catalysis. This led to vibrant and intense creativity in the field of indole synthesis, ${ }^{24}$ modification, functionalization, mostly because of the unique nucleophilicity of indoles combined with the ability of $\mathrm{Au}(\mathrm{I})$ complexes to activate a number of unsaturated bonds. ${ }^{25}$ However, the ratio of enantioselective/non-enantioselective gold-catalyzed functionalization remains quite low, demonstrating that enantioselective gold-catalysis is still challenging in indole chemistry. In this review, we present the established results in the field of enantioselective indole functionalization, focusing on gold catalysis in order to highlight the strength and weaknesses of the area. The papers discussed

a. Université Paris-Saclay, CNRS, Institut de Chimie des Substances Naturelles, UPR 2301, 91198, Gif-sur-Yvette, France. E-mail : xavier.guinchard@cnrs.fr

b. CY Cergy Paris Université, CNRS, BioCIS, 95000, Cergy Pontoise, France.

c. Université Paris-Saclay, CNRS, BioCIS, 92290, Châtenay-Malabry, France. E-mail : angelique.ferry@cyu.fr

${ }^{\S}$ These authors contributed equally. are restricted to enantioselective reactions in which a bond is created between the indole and an electrophile with the concomitant formation of a stereogenic center. Papers where the indole ring is a non-reacting substituent of a scaffold, even in enantioselective gold catalysis, are not included. For each example, the focus will be given on the nature of the catalysts, the ligand design and the mechanisms when relevant.

\section{Reactions with unsaturated functions}

Most of the literature related to the field is dominated by the use of unsaturated functions as the electrophilic partner. Triple bonds, alkenes, allenes, olefins are all suitably activated by the gold complex and are a source of important structural complexity.

\subsection{Triple Bonds}

\subsubsection{Alkynes}

Gold complexes possess a high affinity for alkyne $\pi$-bonds, allowing a selective activation in complex molecular structures. This particularity makes alkynes probably the most used electrophiles in gold catalysis. Gold-catalyzed functionalization of indole heterocycles tethered to alkynes is an attractive and well-developed field. ${ }^{26}$ However, reactions involving indoles and alkynes upon enantioselective gold-catalysis are scarce.

One of the first examples of enantioselective gold-catalyzed functionalization for the synthesis of polycyclic indoles was demonstrated by Bandini in 2012 (Scheme 1). ${ }^{27}$ Indoles tethered to alkyne functions are known to undergo goldcatalyzed spirocyclizations ${ }^{28-36}$ with concomitant indole dearomatization. Compounds $\mathbf{1}$ (X= NTs or diester moiety) undergo hydroindolination of the carbon-carbon triple bond followed by iminium trapping of the alkenyl-gold intermediate. This process leads to the formation of $6 / 5$-fused dihydropyranylindolines $\mathbf{2}$ and 5/7-fused furoindolines $\mathbf{3}$ in high chemo- and regioselectivities. A range of chiral $\mathrm{C}_{2}$-symmetrical bis-phosphine ligands was tested in the cascade reaction by in situ generation of cationic binuclear gold complexes. Optimal 
conditions for the synthesis of tetracyclic furoindolines $\mathbf{2}$ were achieved by the use of 5 mol\% of $(R)$-xylylBINAP $\left(\mathrm{AuBF}_{4}\right)_{2}$ complex with exclusive 5-exo-dig regiochemistry, excellent diastereoselectivities ( $\mathrm{dr}>50: 1)$ and enantioselectivities (ee = 75-87\%). Further expansion to tryptamine-derived propargyl alcohols led to the preferential formation of furoindolines $\mathbf{3} \mathrm{via}$ 7-endo-dig regiochemical pathway using chiral (S)-DTBMSEGPHOS(AuOTf) 2 complex in good yields and enantioselectivities ( $e e=82-85 \%$ ).

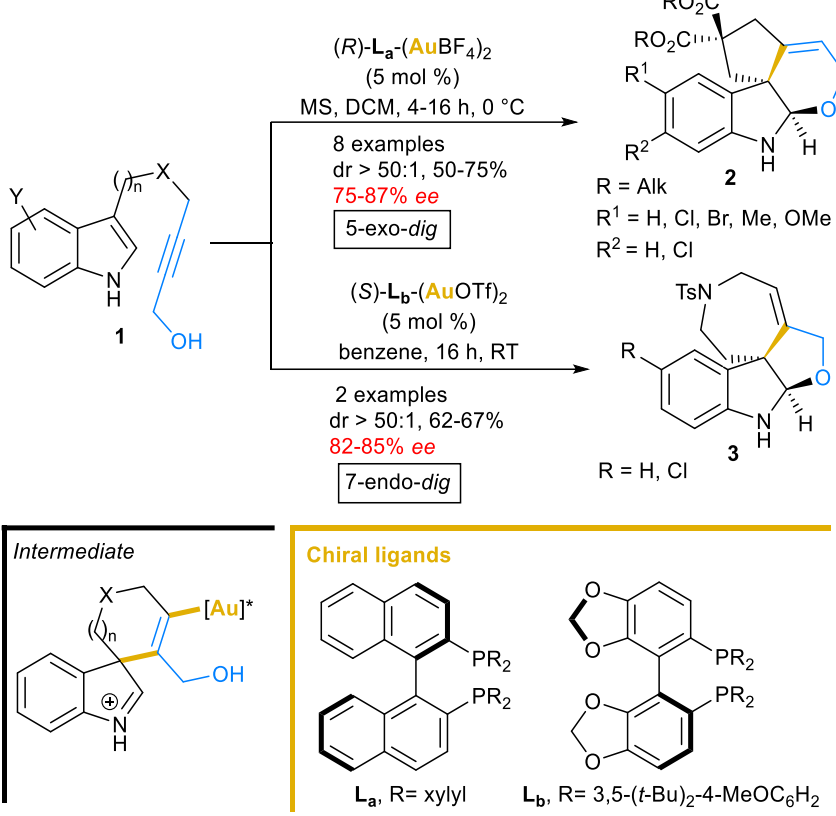

Scheme 1. Intramolecular spirocyclizations of indoles tethered to alkyne function with nucleophilic trapping of the imine.

Interestingly, however, the control of the enantioselectivity is much more difficult when the alkyne is not disubstituted. In 2017, our group developed a gold(I)-catalyzed cyclization of readily available $N$-propargyl tryptamines 4 using 5 mol\% of [JohnPhosAuMeCN]SbF 6 catalyst for the synthesis of spiroindolenines $\mathbf{5}$ (Scheme 2). ${ }^{37}$ The asymmetric version of this reaction was studied using a range of chiral ligands. The use of chiral [Ph-HelPhosS] ligand $\mathrm{L}_{c}$ previously developed in our group $^{38}$ showed the best result providing the desired spiroindolenine product $5 \mathrm{a}$ in $59 \%$ yield and $68 \%$ ee $162 \%$ ee using [(R)-DTBM-BIPHEP(AuNTf $\left.\left.f_{2}\right)_{2}\right]$. Though moderate, this is still the first example of this class of challenging asymmetric spirocyclization under gold catalysis.

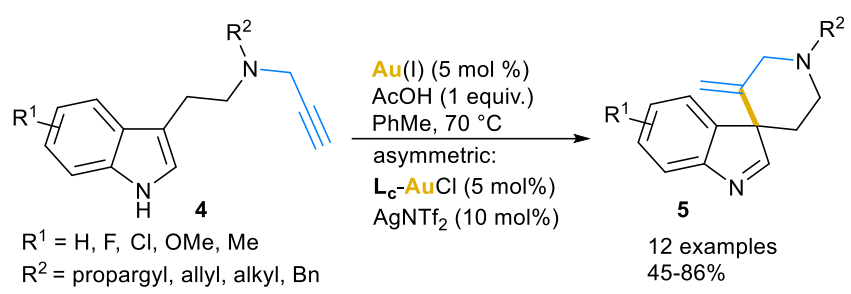

$\mathrm{R}^{2}=$ propargyl, allyl, alkyl, $\mathrm{Bn}$

asymmetric version:

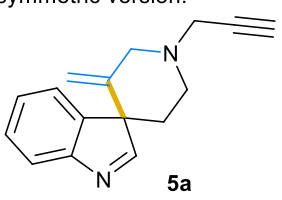

$59 \%$ yield, $68 \%$ ee

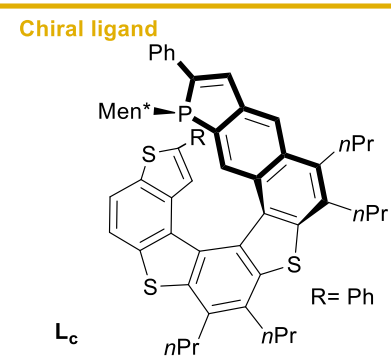

Scheme 2. Intramolecular cyclization of $N$-propargyl tryptamines.

Shi et al. ${ }^{39}$ reported in 2015 an elegant gold(I)-catalyzed cycloisomerization of 1,1-bis(indolyl)-5-alkynes 6 in regio- and enantioselective manner (Scheme 3 ). A series of bis(indole) alkaloids 7 were obtained through a 6-endo-dig cyclization/pseudo 1,5-migration sequence. This reaction was shown to be working perfectly with the $2.5 \mathrm{~mol} \%$ of [Me $\mathrm{MBuXPhosAu}_{4} \mathrm{SbF}_{6}$ gold complex in toluene, providing racemic products 7 up to $99 \%$ yield after 10 minutes of reaction time at room temperature. The enantioselective version of this reaction using $(R)$-DM-SEGPHOS $L_{d}$ as the chiral ligand together with 3,5-dinitrobenzoate (DBN) or 3,5di(trifluoromethyl)benzoate (DTfB) as the counterion, lead to moderate to good ee values. Noteworthy, substrates 6 with $N$ $\mathrm{R}$ linker connected to the propargyl group demonstrated better tolerance $(e e=60-96 \%)$ than the substrate with a gem-diester group $(e e=48 \%)$.

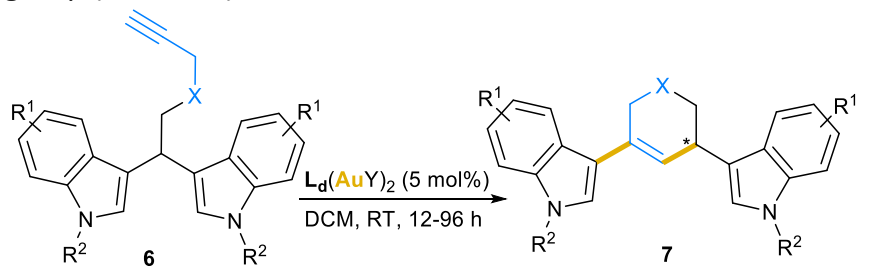

$\mathrm{X}=\mathrm{NTs}, \mathrm{NBs}, \mathrm{NNs}, \mathrm{C}(\mathrm{COOEt})$

$\mathrm{R}^{1}=\mathrm{H}, 4-\mathrm{Cl}, 5-\mathrm{Cl}, 5-\mathrm{Br}, 5-\mathrm{Me}, 5-\mathrm{OMe}, 6-\mathrm{F}, 7-\mathrm{Me} \quad 12$ examples

$\mathrm{R}^{2}=\mathrm{Me}, \mathrm{Bn}$, allyl

$Y=3,5$-dinitrobenzoate or 3,5-ditrifluorobenzoate

$$
55-90 \%
$$
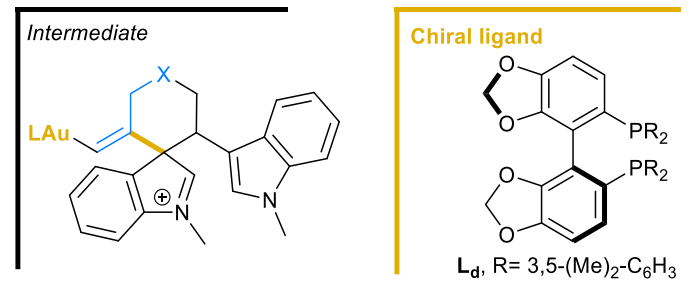

Scheme 3. Synthesis of bis(indole) alkaloids by intramolecular cycloisomerization.

Another efficient enantioselective synthesis of highlyfunctionalized polycyclic indolines $\mathbf{9}$ featuring four contiguous stereocenters was described by Shi the next year (Scheme 4). ${ }^{40}$ Interestingly, in this work, the alkyne functionality was linked to 
the indolic nitrogen and not to the $\mathrm{C} 3$ or $\mathrm{C} 2$ carbons. This resulted in a new type of 5/7-fused polycyclic compounds 9 connected through the nitrogen atom. With the racemic cyclization conditions of indolyl propargylic esters $\mathbf{8}$ in hand, the authors developed the asymmetric version using Feringa phosphoramidate $\mathbf{L}_{\mathbf{e}}$ as the best chiral ligand, leading to $80-91 \%$ $e e$ values. The complex mechanism for this cascade cyclization reaction involves a 1,2-acyloxy migration and a [3+2] cycloaddition as key steps.

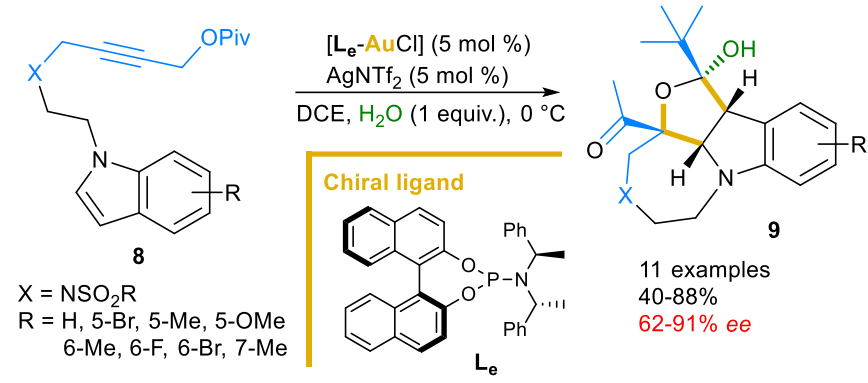

Scheme 4. Intramolecular cascade cyclization route to polycyclic indolines.

In 2015, Toste reported the access to enantioenriched cyclopenta[ $b]$ indoles $\mathbf{1 1}$ by the first gold-catalyzed dearomative Rautenstrauch rearrangement of propargyl acetates $\mathbf{1 0}$ using (S)-DTBM-SEGPHOS(AuSbF6) ${ }_{2} \quad$ (Scheme 5). ${ }^{41}$ The enantioselectivity was well controlled by the chiral ligand during the imino-Nazarov cyclization of intermediate $\mathbf{I}$ to the next intermediate II. After de-coordination of gold and hydrolysis, the desired cyclopenta[b]indoles $\mathbf{1 1}$ were obtained in good 7191\% yields and high enantioselectivities $71-97 \%$ ee.

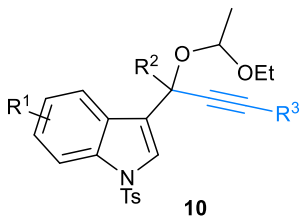

1. $(S)-L_{b}-(A u C l)_{2}$ $\underset{\text { 2. PTSA. } \mathrm{H}_{2} \mathrm{O} \text {, acetone/ } \mathrm{H}_{2} \mathrm{O}}{\stackrel{\mathrm{AgSbF}_{6}, 4 \AA \mathrm{MS}, \mathrm{DCM}}{\longrightarrow}}$

$\mathrm{R}^{1}=\mathrm{H}, \mathrm{F}, \mathrm{Me}, \mathrm{OMe}$

$\mathrm{R}^{2}=\mathrm{Me}, \mathrm{Et}, n-\mathrm{Bu}$

$\mathrm{R}^{3}=\mathrm{CO}_{2} \mathrm{Alk}, \mathrm{COPh}, \mathrm{COEt}$

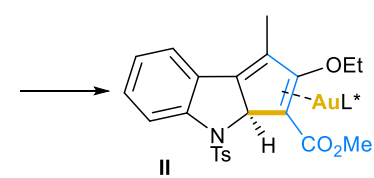

II

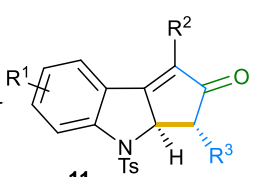

16 examples $46-90 \%$

$$
\text { Enantiodetermining step }
$$

Scheme 5. Intramolecular dearomative Rautenstrauch rearrangement of indolyl propargyl acetates.

\subsubsection{Ynamides}

Ynamides are another kind of highly electron-rich triple bonds that are easily activated by gold-complexes. Following previous work of Bandini with propargylic alcohols, Gong and Yang reported the gold-catalyzed intramolecular cyclization of ynamides 12. This reaction proceeds via an intramolecular trapping of the intermediate iminium by the alcohol providing 6/5-fused pyrrolidinoindolines 13 in 52-94\% yields (Scheme 6). ${ }^{42} \mathrm{~A}$ number of chiral ligands were tested, leading to the

identification of (S)-Ph-MeO-BIPHEP $\mathbf{L}_{\mathbf{f}}$ as the best chiral ligand, providing the enantioenriched product $\mathbf{1 3}$ in a moderate $60 \%$ $e e$. This shows that discrimination of one of the geometries of the keteneiminium by chiral ligand during the coordination of starting ynamide with the chiral gold complex is not an easy task. Surprisingly, the non-bulky ligand $\mathbf{L}_{f}$ was the best one here, whereas the same ligand with phenyl groups was unsuccessful in most enantioselective gold-catalyzed processes.<smiles>[R3]c1cccc2c1c(CCN([R])C#CC([R])O)c([R])n2[R12]</smiles>

$\mathrm{R}^{1}=\mathrm{Me}, \mathrm{Bn}, \mathrm{PMB}$, allyl $\mathrm{R}^{2}=\mathrm{Ts}, \mathrm{Ns}, \mathrm{Ms}$ $\mathrm{R}^{3}=\mathrm{H}, 4-\mathrm{CO}_{2} \mathrm{Me}, 5-\mathrm{Hal}, 5-\mathrm{EWG}, 6-\mathrm{Me}, 7-\mathrm{OMe}$ $\mathrm{R}^{4}=\mathrm{H}, \mathrm{Me}, \mathrm{F}$ $\mathrm{R}^{5}=\mathrm{H}, \mathrm{Me}$
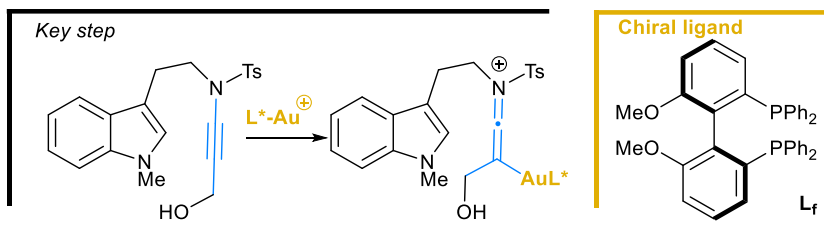

Scheme 6. Intramolecular cyclizations of ynamides to tetracyclic indolines.

Recently, Ohno et al. ${ }^{43}$ developed the asymmetric synthesis of pyrrolo[2,3-d]carbazole core $\mathbf{1 5}$ of aspidosperma alkaloids based on a gold-catalyzed cascade reaction of ynamide with silyl enol ether 14 as the terminal nucleophile (Scheme 7). The optimal conditions using 5 mol\% of (R)-DTMB-SEGPHOS(AuCl $)_{2}$ chiral complex and sodium tetrakis[3,5-bis(trifluoromethyl)phenyl]borate (NaBARF) led to moderate $38 \%$ yield but provided ready access to the synthetic intermediate $\mathbf{1 5}$ of vindorosine alkaloid with good enantioselectivity $(74 \% e e)$.

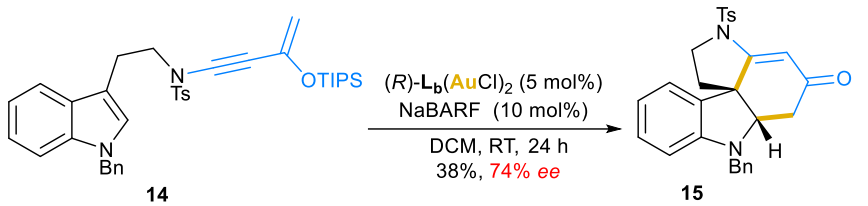

Scheme 7. Intramolecular cascade reaction of indolyl ynamide to pyrrolo[2,3-d]carbazole.

\subsection{Allenes and related unsaturated functions}

Allenes figure among the most used electrophilic partners in gold catalysis, ${ }^{44}$ and their reactions with indoles have been particularly studied ${ }^{25}$ both in an inter- and intramolecular manner. With their axial chirality and various coordination modes, allenes have met particular success in enantioselective $\mathrm{Au}(\mathrm{I})$-catalysis.

\subsubsection{Intermolecular reactions with allenes}

Following the precursor reports of Widenhoefer in 2009, ${ }^{45}$ Che et al. developed the intermolecular reactions of indoles 16 with symmetrical allenes 17 . The best conditions used (S)-Ph-MeOBIPHEP $L_{g}$ and $\mathrm{AuCl}$ as the chiral binuclear gold(I) phosphine complexes, displaying intramolecular $\mathrm{Au}(\mathrm{I})-\mathrm{Au}(\mathrm{I})$ interactions in combination with silver salt (Scheme 8). ${ }^{46}$ Diverse di-arylallenes 17 were used leading to high yields (up to 90\%) but only 
with moderate enantioselectivities (up to $63 \%$ ee) of the $E$ isomer as the sole products 18 . The presence of orthosubstituents on the aryl ring on allenes resulted in a significant decrease in the yield and the enantioselectivity. Similarly, the electron-withdrawing group on these aryl rings are detrimental in the enantiocontrol. Allenes substituted with alkyl groups were unsuccessful in these conditions. This rare example of intermolecular enantioselective reaction with allenes reveals the high challenge associated with the stereocontrol in this reaction, despite a thorough chiral ligand screening. The authors showed in this reaction that Au-Au interaction in the catalyst appear crucial to the enantiodiscrimination since more flexible binuclear digold complexes with no $\mathrm{Au}-\mathrm{Au}$ interaction showed lower ee values.

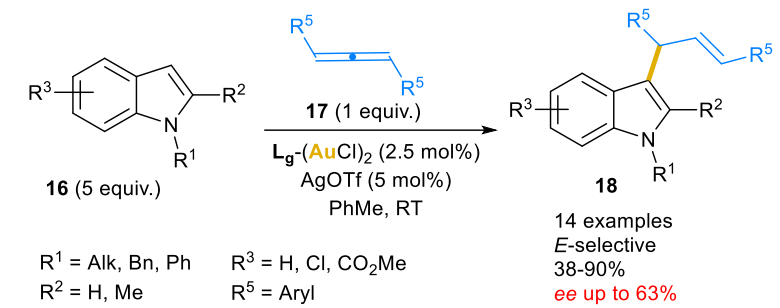

Scheme 8. Intermolecular hydroarylation of allenes with indoles.

\subsubsection{Intramolecular reactions with allenes}

When the allene is tethered to the indole, gold activation triggers an intramolecular cyclization, which is usually more favorable for the enantioinduction. Widenhoefer's group developed in 2006 the first reactions between indoles and allenes using a catalytic amount of $\mathrm{AuCl}$ and a silver salt. ${ }^{47}$ The enantioselective version was then reported using the $\mathrm{AuCl}$ complex of (S)-DTBM-MeO-BIPHEP $L_{h}$ and $\mathrm{AgBF}_{4}$ (Scheme 9). ${ }^{48}$ Diverse 2-allenyl indoles 19 were used leading to high (80-90 \%) yields of products $\mathbf{2 0}$ with moderate to high enantioselectivities (60-98\% ee). The presence of an electron-withdrawing group at $R^{2}$ seems required to ensure a good enantioselectivity.

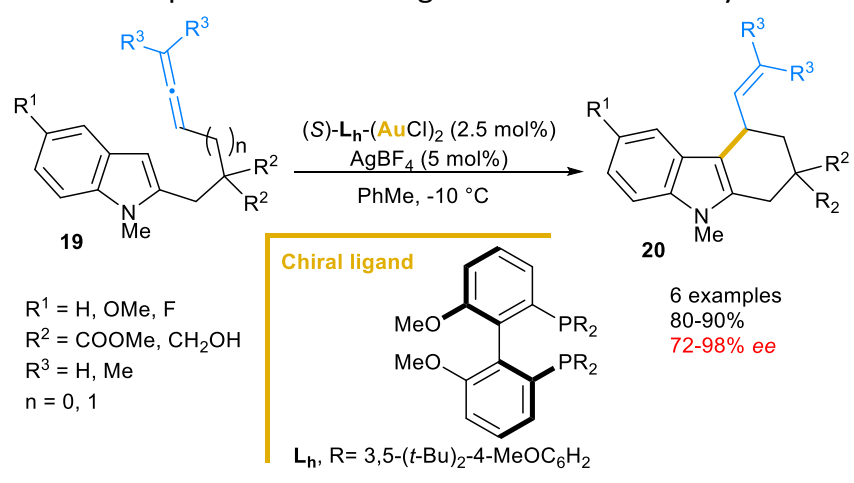

Scheme 9. Intramolecular cyclization of 2-allenyl indoles.

When the allene function is in a 1,6-relationship with the nucleophilic indole ring, spirocyclization can occur. In 2019, Shi et al. have reported kinetic resolutions from racemic $N$ homoallenyl tryptamines $\mathbf{2 1}$ to form spirofused complex polycyclic indole 22 (Scheme 10). ${ }^{49}$ The (R)-DTBM-SEGPHOS gold complex $\mathbf{L}_{\mathbf{b}}-(\mathrm{AuCl})_{2}$ coordinates preferentially to the $(S)$ - configured isomer, to give a tetracyclic compound, while the $(R)$ isomer is left alone and sees its enantiomeric excess rising. With this methodology, two different targets can be accessed starting from one racemic compound, with good yields (maximum $50 \%$ for each compound) and good ee values. The same group extended this reactivity to the desymmetrization of allenyl bisindole 23 with the same catalyst in 2019 (Scheme 10). ${ }^{50}$ Because of the symmetry of the starting material, high yields can be obtained via this desymmetrization. Alternative linkers have been investigated, but tryptamine derivatives seem to be preferred for those kinds of reactions. Noteworthy, these reactions do not work with non $\mathrm{N}$-substituted indoles. The reactions evolve through intermediate $\boldsymbol{I}$ after the first cyclization, and the iminium is then trapped by the vinylgold intermediate forming gold carbene II (Scheme 10). A combination of deuterium labeling and DFT calculations confirmed this mechanistic scenario.

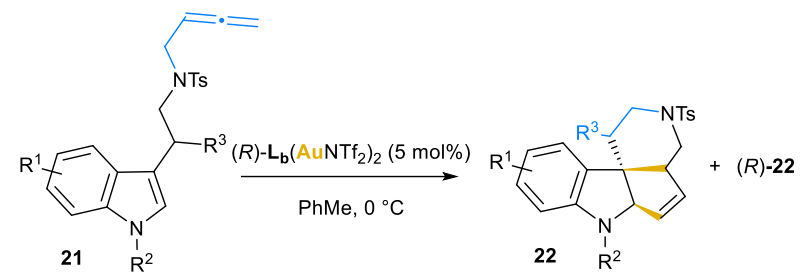

$\mathrm{R}^{1}=\mathrm{H}, \mathrm{Me}, \mathrm{F}, \mathrm{Cl}, \mathrm{Br}$, COOMe, OMe $\mathrm{R}^{2}=\mathrm{Bn}$, Allyl, $\mathrm{Me}$ 25 example $34-49 \%$

$\mathrm{R}^{3}=\mathrm{Ar}$, Vinyl, $\mathrm{CHCHCOOEt}, \mathrm{CH}_{2} \mathrm{CH}_{2}$ COOEt, $\mathrm{C}_{4} \mathrm{H}_{9}$ $\mathrm{C}_{2} \mathrm{H}_{5} \mathrm{COCH}_{3}, \mathrm{C}_{3} \mathrm{H}_{6}$ OTBS

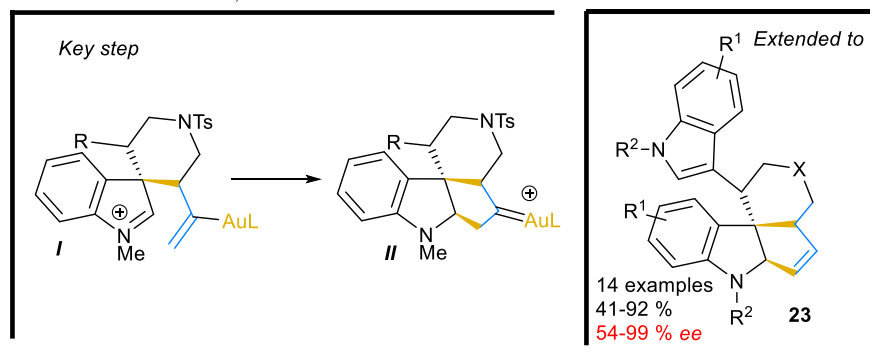

Scheme 10 . Kinetic resolutions of racemic $N$-homoallenyl tryptamines.

In 2017, the Toste group established the enantioselective version $^{51}$ of a tandem rearrangement/cyclization process initially developed by Zhang (Scheme 11, eq. 1).52 The process initiates from indole propargyl esters 24 that rearrange to the allenyl ester I via a 3,3-sigmatropic rearrangement promoted by the $\mathrm{Au}(\mathrm{I})$ complex. The allene function, hence generated in situ undergoes a [2+2] cyclization to the polycyclic indoles 25 . In this work, Toste reported a method to analyse the independent structural features of acyclic diaminocarbenes (ADC) ligands, allowing to correlate and predict mathematical models of enantioselectivity. Based on that, the best catalyst was found to be the chiral acyclic diaminocarbene gold complex $\mathbf{L}_{\mathbf{i}}$. The scope of reaction was then tested on a series of propargylic esters $\mathbf{2 4}$ to show a good level of substituent tolerance providing the 2,3indoline-fused cyclobutanes 25 in $69-98 \%$ yields and $82-94 \%$ ee values.

Very recently, our group reported that $N$-homoallenyl tryptamines $\mathbf{2 6}$ behave the same as intermediates allenes generated in Toste's system, ${ }^{51}$ leading to spirofused compounds 
27 (Scheme 11, eq. 2). ${ }^{53}$ Newly designed HelPhos chiral ligands $\mathbf{L}_{\mathbf{j}}$ were used as their chiral gold complexes ensuring high enantioselectivities in a range of compounds. Interestingly, the replacement of the unsubstituted catalyst $(\mathrm{R}=\mathrm{H})$ by an alkyne substitution ( $\mathrm{R}=-\mathrm{C} \equiv \mathrm{C}-\mathrm{Ph})$ led to an increase of the enantioselectivities, as previously observed in other enantioselective gold-catalyzed processes. ${ }^{54}$ The vinylgold key intermediate II is common to our work and Toste's report and traps the iminium function. Interestingly, the iminium is trapped here by the carbon bearing the gold atom, as opposed to previous work of Shi for which the similar intermediates evolved through the formation of a carbene and finally the generation of a five-membered ring (See Scheme 10, key step). ${ }^{55}$ Interestingly too, monosubstituted allenes were not suitable in neither of these reactions, though it was working well in Shi's work. This may be linked to the fact that the indole has to be $N$ substituted in Shi's work, to ensure sufficient electrophilicity of the intermediate iminium.

Eq 1: Toste, 2017

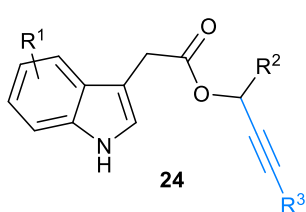

$\mathrm{R}^{1}=\mathrm{H}$, halogen, Me, OMe $R^{2}, R^{3}=A l k, A r$

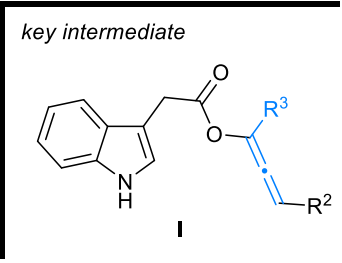

Eq 2: Voituriez, Guinchard, 2020

$\mathrm{R}$
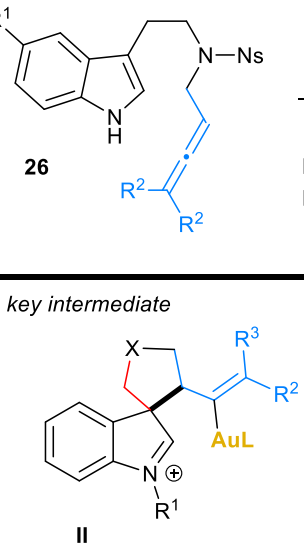

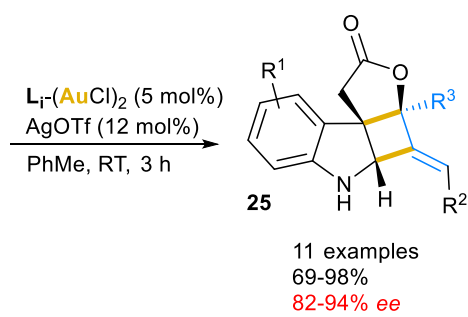

Chiral Au(I) complex $\quad \mathrm{L}_{\mathbf{i}}-(\mathrm{AuCl})_{2}$

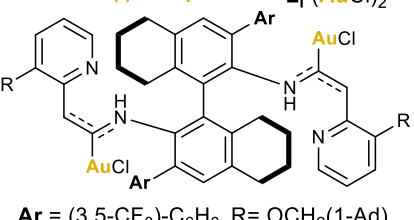

$\mathrm{Ar}=\left(3,5-\mathrm{CF}_{3}\right)-\mathrm{C}_{6} \mathrm{H}_{3}, \mathrm{R}=\mathrm{OCH}_{2}(1-\mathrm{Ad})$
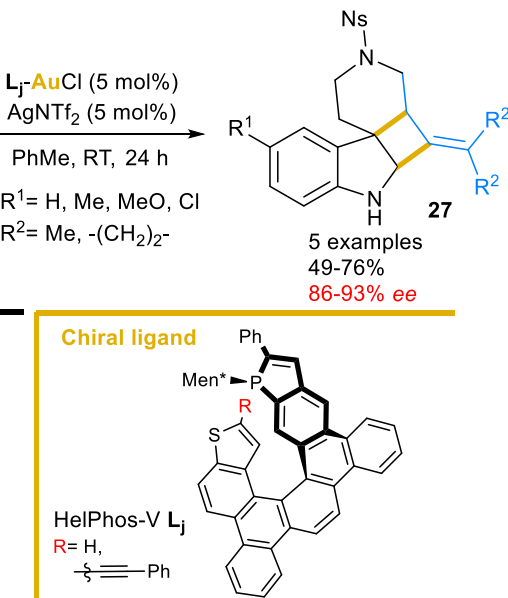

Scheme 11. Formation of cyclobutane-fused polycyclic indoles derivatives via [2+2] cyclizations.

\subsubsection{Allenamides}

In 2015, Chen et al. extended the hydroarylation reactivity to the asymmetric gold-catalyzed annulation of tryptamines or tryptols $\mathbf{2 8}$ with allenamides, which furnished pyrroloindolines, and furoindolines $\mathbf{2 9}$ with moderate to excellent ee's (Scheme
12, eq. 1). ${ }^{56}$ The enantioselectivity was here controlled by two different BINOL derived phosphoramidite ligands $\mathbf{L}_{\mathbf{k}}$ and $\mathbf{L}_{\mathbf{l}}$, depending on the substrate. The same year, Bandini et al. showed that 2,3-disubstituted indoles and allenamides undergo a [2+2]-cycloaddition process. ${ }^{57}$ This process is favored by the use of an electron-rich phosphine on the gold complex and the presence of an EWG at the $N(1)$ position (Boc, Cbz), enhancing the electrophilicity of the iminium intermediate. These two parameters prevent the protodeauration process and allow the formation of the cis methylene 2,3-cyclobutane-fused indolines 31 bearing two quaternary stereocenters and possessing a $(Z)$ exo carbon-carbon double bond. The use of chiral (R)-DTBMSEGPHOS ligand $\mathbf{L}_{b}$ coordinated-gold complex in the presence of $\mathrm{AgNTf}_{2}$ as activator furnished $\mathbf{3 1}$ in modest to excellent ee's (Scheme 12, conditions A). In the presence of allenamides, the same chiral catalyst enabled the enantioselective formation of 31 with excellent diastereo- and enantioselectivities (dr>20:1, ee's up to $99 \%$ ) with the (Z)-configuration for the exocyclic double bond (Scheme 12, conditions B). ${ }^{58}$ Allenamides usually presented a higher reactivity than aryloxyallenes. DFT calculations evidenced for a two-step process, namely the dearomative $\mathrm{C}-\mathrm{C}$ bond formation (being rate-determining step) followed by the formation of the cyclobutane ring. Recently, Chen et al. developed a series of axially chiral gold complexes $L_{m}$ possessing a bis-triazole-type scaffold and showed that this new class of chiral $\mathrm{Au}(\mathrm{I})$ complex does not have aurophilic interactions. ${ }^{59}$ These catalysts were applied in the enantioselective [2+2]-cycloaddition of 2,3-dimethylindole with allenamide leading, however, to moderate enantiomeric excess (Scheme 12, conditions C). 
Eq. 1: Chen 2015, addition to allenamides with trapping by external nucleophile
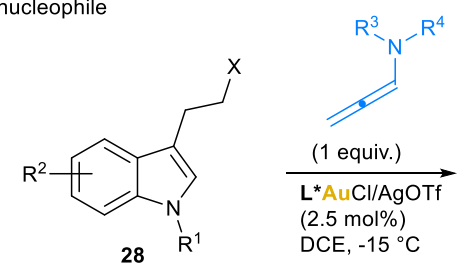

DCE $-15^{\circ} \mathrm{C}$

$\mathrm{Cl}, \mathrm{Br}, \mathrm{OMe}$

$\mathrm{R}^{1}=\mathrm{Me}, \mathrm{Bn}, \mathrm{H} ; \mathrm{R}^{2}=$
$\mathrm{X}=\mathrm{NHTs}, \mathrm{NHMs}, \mathrm{OH}$

$\mathrm{X}=\mathrm{NHTs}, \mathrm{NHMs}, \mathrm{OH}$
$\mathrm{R}^{3}, \mathrm{R}^{4}=\mathrm{Ts}, \mathrm{Ar}, n-\mathrm{Bu}$,
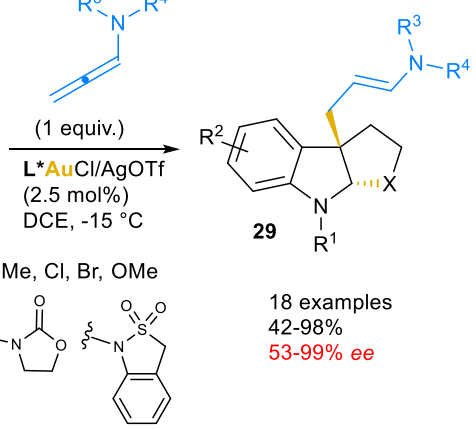

18 examples

$42-98 \%$

$53-99 \%$ ee

Eq. 2: Formal [2+2] cycloaddition processes with allenamides and aryloxyallenes<smiles>[R]c1ccc2c(c1)c([R])c([R])n2[R]</smiles>

30 (2 equiv.)

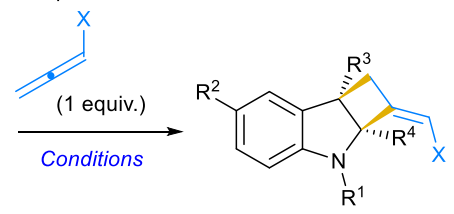

31 Z-selective

\begin{tabular}{lll}
$\quad$ A & \multicolumn{1}{c}{$B$} & \multicolumn{1}{c}{$C$} \\
$\mathrm{X}=$ OAr & $\mathrm{X}=$ NRR' & $\mathrm{X}=\mathrm{NRR}^{\prime}$ \\
6 examples & 17 examples & 2 examples \\
$32-74 \%, \mathrm{dr}>20: 1$ & $41-96 \%, \mathrm{dr}>20: 1$ & $70 \%$ \\
$64-95 \%$ ee & $81-99 \%$ ee & $64 \%$ ee
\end{tabular}

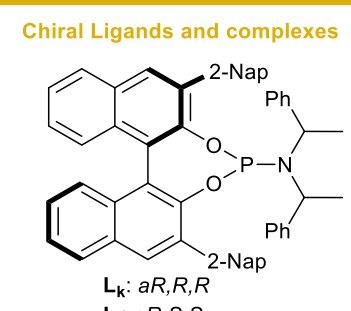

$\mathbf{L}_{\mathbf{l}}: a R, R, R, S$
a

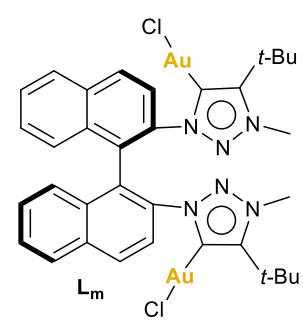

Scheme 12. Intermolecular reactivities of indoles with allenamides/aryloxyallenes.

In 2013, Vicente and Rossi extended this methodology in a racemic manner to 2 -vinylindoles ${ }^{60}$ When the Gagosz catalyst ${ }^{61}$ $\mathrm{Ph}_{3} \mathrm{PAuNTf}_{2}$ was used with $\mathrm{N}$-methyl or $\mathrm{N}$-H 2-vinylindoles, the classical hydroarylation process occurs. However, with EWG on the indole nitrogen, the intermediate iminium becomes more electrophilic, driving a gold-catalyzed [4+2] cycloaddition to form tetrahydrocarbazoles derivatives. Xia and Zhang next developed enantioselective version of this [4+2]-cycloaddition between $\mathrm{N}$-(carbamoyl)-3-vinylindoles $\mathbf{3 2}$ and allenamides $\mathbf{3 3}$ using a chiral $\mathrm{H}_{8}$-BINOL-derived phosphoramidite ligand (Scheme 13, eq. 1).62 Various tetrahydrocarbazoles 34 could be obtained in good to excellent yields with a (Z)-selectivity up to 14:1 and excellent ee's.

In 2017, Rossi and Pirovano et al. developed a variant of this enantioselective cycloaddition between 2-vinylindoles $\mathbf{3 5}$ and allenamides $36,{ }^{63}$ using $(R)$-DTBM-SEGPHOS $\mathbf{L}_{b}$ as the chiral ligand. Diverse 2-vinylindoles 35 bearing both EWG and EDG were successfully transformed in these conditions leading to the corresponding products $\mathbf{3 7}$ with good ee's (Scheme 13, eq. 2 ) as the $(Z)$-isomers only. A low temperature $\left(-40^{\circ} \mathrm{C}\right)$, as well as the excess of allenamide partners, were key parameters in the optimization process. However, the presence of alkyl substitution on a vinyl part is deleterious on the enantioselectivity, but the reaction tolerated C3-substituents such as hydrogen, methyl or ethyl. These conditions could then be applied to 3-vinylindoles furnishing the corresponding carbazoles 37 in excellent yield (80-97\%) and good ee (76-98\%) on four examples but as a mixture of $(Z)$ and $(E)$ isomers (not shown). Finally, in 2016, Rossi and Pirovano preliminary reported the enantioselective version of a new cyclization leading to compound $\mathbf{3 8}$ in good yield and a $70 \%$ ee using ligand Lo (Scheme 13). ${ }^{64}$

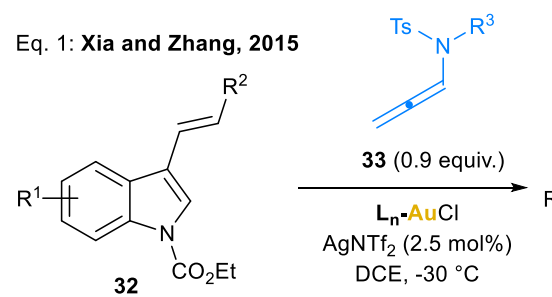

$\mathrm{R}^{1}=\mathrm{H}, \mathrm{OMe}, \mathrm{Me}, \mathrm{Br} ; \mathrm{R}^{2}=\mathrm{Ar}, n-\mathrm{Pr}, \mathrm{H} ; \mathrm{R}^{3}=\mathrm{Ar}$

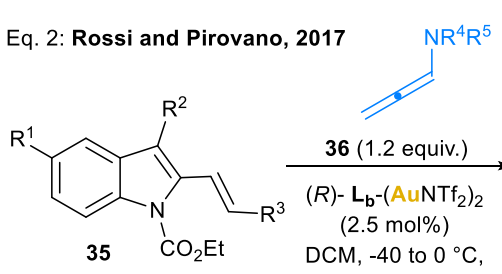

$\mathrm{R}^{1}=\mathrm{H}, \mathrm{Cl} ; \mathrm{R}^{2}=\mathrm{H}, \mathrm{Me}, \mathrm{Et}$

$\mathrm{R}^{3}=\mathrm{Ar}, n-\mathrm{Pr}$

$\mathrm{NR}^{4} \mathrm{R}^{5}=\mathrm{NTsMe}$

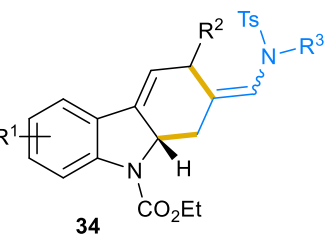

Z-selective

12 examples

$82-99 \%(Z+E)$

$\mathrm{dr}>99 \cdot 1$

$88-97 \%$ ee

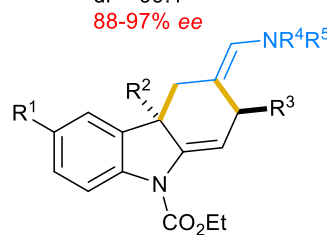

$37 \quad \mathrm{CO}_{2} \mathrm{Et}$

8 examples

$40-90 \%, d r>99: 1$ er up to $97: 3$

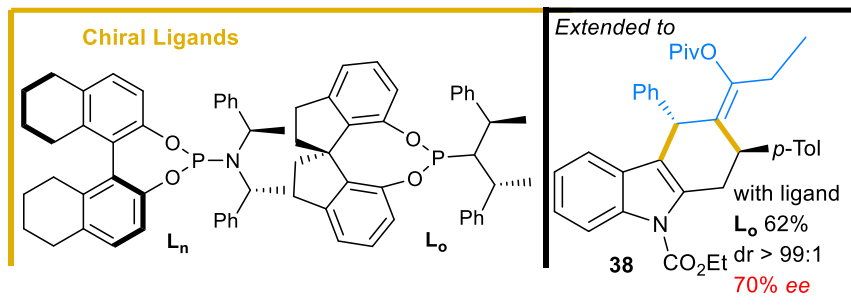

Scheme 13. Cycloaddition between vinylindoles and allenamides.

This methodology was then extended to the isomeric 3-allenyl indoles, particularly on tryptamine derivatives 39 by Zhang et al. in 2017 (Scheme 14). ${ }^{65}$ During this work, a chiral bifunctional sulfonamide monophosphine ligand $L_{p}$ was used. Nosyl and tosyl $\mathrm{R}^{3}$ groups led to good enantioselectivities (>77 \% ee), but the TRIS group was the one that showed the best ee. With this group, the substitution of the indole has been studied, leading to high yields (>90\%) and enantioselectivities (> 86\% ee). Unfortunately, it was also shown that substitution of the allenamide $\left(R^{4} \neq H\right)$ led to low enantioselectivity. Interestingly, the desymmetrization reaction of bisindole starting materials has been studied and led to high ee's and diastereoselectivities for compounds $\mathbf{4 1}$ (See scheme 14). These approaches provide an interesting alternative to classical enantioselective strategies to access chiral tetrahydro- $\beta$-carbolines, for which organocatalysis is not so efficient as far as 1 -vinyl-TH- $\beta$-Cs are concerned. ${ }^{66-68}$ 


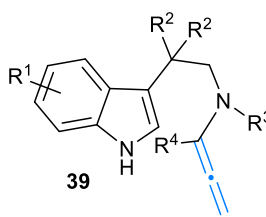

$\mathrm{R}^{1}=\mathrm{H}, \mathrm{OR}, \mathrm{Alk}, \mathrm{Ph}, \mathrm{F}, \mathrm{Br}$ $\mathrm{R}^{2}=\mathrm{H}, \mathrm{Me}$

$\mathrm{R}^{3}=\mathrm{Ts}, \mathrm{Ns}, \mathrm{Ms}, \mathrm{TRIS}, \mathrm{Ar}$ $\mathrm{R}^{4}=\mathrm{H}$

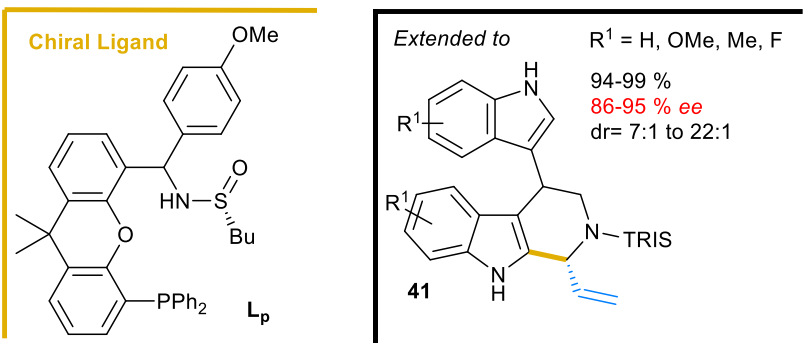

Scheme 14. Synthesis of chiral tetrahydro- $\beta$-carbolines via intramolecular cyclization of indoles to allenamides.

\subsection{Allylic alcohols}

Bandini et al. showed the reactivity of $\pi$-activated alcohols in the first enantioselective gold-catalyzed intramolecular Friedel-Crafts alkylation of indoles. ${ }^{69,} 70$ Starting from (Z)-42 (Scheme 15), this transformation allowed the formation of enantioenriched 1vinyltetrahydrocarbazoles $\mathbf{4 3}$ using the C2-symmetric biphosphine (S)-DTBM-MeO-BIPHEP $L_{h}$ chiral ligand. The triflate gold-counterion appeared to be crucial to obtain the optimal reactivity and stereoinduction. These conditions tolerate a wide range of electronwithdrawing and -donating functional groups on the indole ring. Tricyclic compounds $\mathbf{4 3}$ were then obtained in good yields and high enantiomeric excesses. The (Z)-configuration of the $\mathrm{C}=\mathrm{C}$ bond of the acyclic precursor is necessary to observe the described reactivity. Using isomeric starting material, the authors could access 4vinyltetrahydrocarbazoles or 4-vinyltetrahydro- $\beta$-carbolines $\mathbf{4 4}$ with good enantioselectivities. DFT computations suggested that the mechanism of these transformations involves a single-site interaction mode involving a monogold-activation leading to intermediate $\boldsymbol{I}$, for which the rearomatization is the rate-limiting step, combined then with a Brønsted acid assisted $\beta$-hydroxy elimination process from $\mathbf{~ I . ~}{ }^{71}$
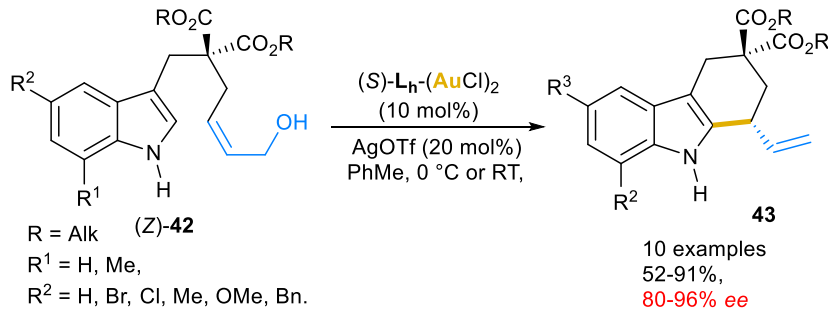

$\begin{array}{lll}\mathrm{R}^{2} & \mathrm{H} & \mathbf{4}\end{array}$

$\mathrm{R}^{2}=\mathrm{H}, \mathrm{Br}, \mathrm{Cl}, \mathrm{Me}, \mathrm{OMe}, \mathrm{Bn}$

$$
\begin{aligned}
& 10 \text { examp } \\
& 52-91 \% \text {, }
\end{aligned}
$$
$80-96 \%$ ee

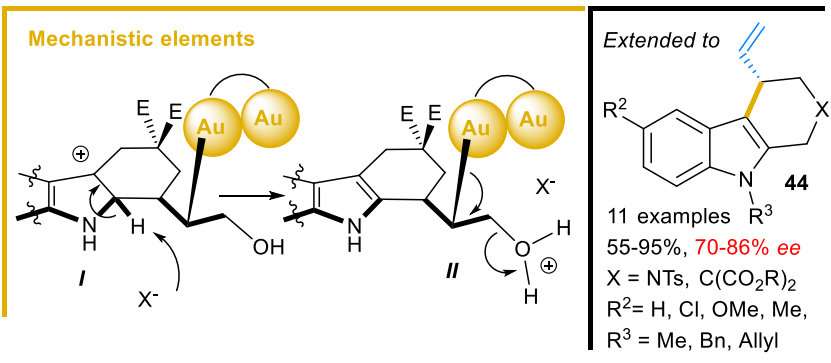

Scheme 15. Access to 4-vinyltetrahydrocarbazoles by intramolecular Friedel-Crafts alkylation.

\subsection{Pictet-Spengler Reactions}

Recently, our group reported that tryptamines $\mathbf{4 5}$ and aldehydes 46 undergo enantioselective Pictet-Spengler reactions in the presence of a chiral gold-complex to form tetrahydro- $\beta$-carbolines 47 (Scheme 16). ${ }^{72}$ Screening of chiral ligands revealed that $(R)$-DM-SEGPHOS $L_{d} A u(I)$ complex led to the best enantioselectivities, ranging mostly from 72 to $96 \%$ ee. The nature of the $\mathrm{R}^{2}$ group proved crucial to obtain the highest enantioselectivities. The reaction, though efficient, was, however, limited to the use of aromatic aldehydes. This reactivity is somewhat unexpected for $\mathrm{Au}(\mathrm{l})$ complexes that are weak Lewis acids, despite the precedence of both $\mathrm{Au}$ (III) and $\mathrm{Au}(\mathrm{I})$-catalyzed non-enantioselective reactions. $73,74,75$ The mechanistic hypothesis explains how the iminium can be formed while the reaction is performed in the strict absence of any acidic proton. It relies on the auration of the indole ring generating intermediate $\mathbf{I}$, from the reaction of the tryptamine gold-complex I with the aldehyde followed by the dehydration of the intermediate hemiaminal. Once formed, intermediate II is nucleophilic enough to trap the iminium species to reach intermediate III, that deaurate to release the final product.

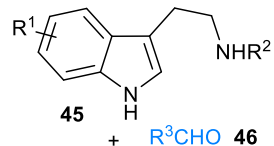

\section{$\underset{\mathrm{AgNTf}_{2}(5.8 \mathrm{~mol} \%)}{\stackrel{(R)-\mathrm{L}_{\mathrm{d}}-(\mathrm{AuCl})_{2}(3 \mathrm{~mol} \%)}{\longrightarrow}}$ DCM, RT, 4 Å MS}

$\mathrm{R}^{1}=\mathrm{H}, \mathrm{OMe}, \mathrm{Me}$, halogen $\mathrm{R}^{2}=\mathrm{Bn}$, allyl, $p-\mathrm{MeOC}_{6} \mathrm{H}_{4}$ $p-\mathrm{MeOC}_{6} \mathrm{H}_{4}, \mathrm{CH}_{2} \mathrm{Mes}$ $\mathrm{R}^{3}=\mathrm{Ar}$, heteroary

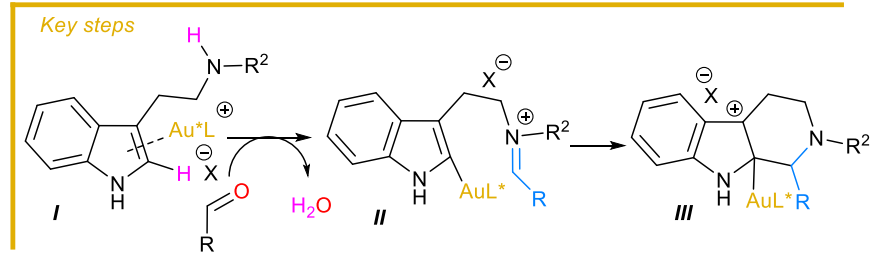

Scheme 16. Gold-catalyzed enantioselective Pictet-Spengler reactions.

\section{Reactions involving indoles as an external nucleophile}

Since the rise of homogeneous gold catalysis in the first decade of the century, cycloisomerizations have been one of the major class of reactions to be studied in details. ${ }^{76-78}$ Those reactions are of infinite richness in terms of structural complexity since they combine in general two unsaturated arms. In a number of reactions, the late stage of the mechanistic pattern involves the formation of a carbocation that can be trapped by a nucleophile. With its exceptionally high nucleophilicity, the indole ring is very often used as a randomly assayed nucleophile in a vast number of reactions in organic synthesis, including in cycloisomerizations. In particular, over the last decade, the indole trapping of electrophilic gold carbenes species formed by reaction with 1,6-enynes was largely explored. In 2007, 
Echavarren showed that the activation of 1,6-enyne substrates 48 by cationic gold(I) complexes generated, via a 5-exo-dig cyclization (Scheme 17, eq. 1), a cyclopropyl gold carbene intermediate $I$ which could be attacked by electron-rich arenes such as indoles in two different sites namely the cyclopropane (Pathway 1) and the carbene (Pathway 2), followed by rearomatization of the indole and protodemetalation. Most of the tested catalysts lead to compounds $49 \mathrm{a}$ as the major products (Pathway 1). On the contrary, bulky NHC-Au complexes favor the formation of $49 \mathrm{~b}$ (Pathway 2). ${ }^{79,80,81,82}$ The first enantioselective version of this reaction was reported by Michelet et al. using (R)-DTBM-MeO-BIPHEP-(AuCl $)_{2}$ complex combined to silver salt under mild conditions (Scheme 17, eq. 2 , conditions A), ${ }^{83,84}$ leading to $\mathbf{5 1 a}$ as single anti diastereoisomers in good to excellent enantiomeric excesses. The authors suggested that both the cyclization and the addition of the nucleophile may be concerted. Michelet, Toullec and Mézailles reported later 85 alternative conditions using undecagold clusters bearing chiral phosphine ligands $\mathbf{L}_{\boldsymbol{f}}$ or BINAPand best conditions resulted in $99 \%$ yield and $44 \%$ ee of a member of series of compound 51a $\left(\mathrm{X}=\mathrm{C}\left(\mathrm{CO}_{2} \mathrm{Me}\right)_{2}, \mathrm{R}^{1}=\mathrm{R}^{3}=\mathrm{H}, \mathrm{R}^{2}=\mathrm{Me}, \mathrm{R}^{4}=\right.$ $\mathrm{Ph})$, which was comparable to the previously reported result ${ }^{83}$ (91\% yield, 45\% ee, Scheme 17, eq. 2, conditions A). Later, Shi et al. proposed new axially chiral NHC gold complex $\mathrm{L}_{\mathbf{q}}$ catalyzing the formation of 51a in good yields and with excellent diastereoisomeric ratios but with moderate to good enantioselectivities (Scheme 17, eq. 2, conditions B). ${ }^{86}$

Eq. 1: Mechanistic pathways in enyne cycloisomerizations

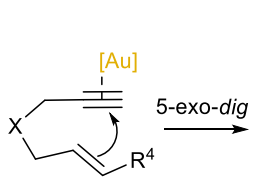

48

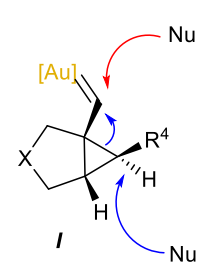

Eq. 2: Michelet 2009 and Shi 2011

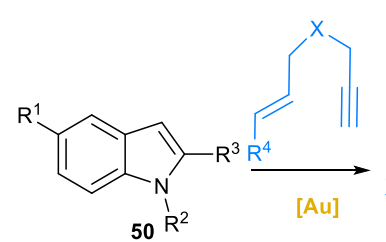
$50 R^{2}$

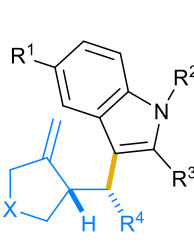

$51 \mathrm{a}$

Conditions A:

$(R)-\mathrm{L}_{\mathrm{h}}-(\mathrm{AuCl})_{2}(3 \mathrm{~mol} \%)$, AgOTf (6 $\mathrm{mol} \%), \mathrm{Et}_{2} \mathrm{O}, \mathrm{RT}, 15-20 \mathrm{~h}$

8 examples , $37-99 \%, \mathbf{5 1} \mathbf{a} / \mathbf{5 1} \mathbf{b}=>99 / 1$

$36-95 \%$ ee

$\mathrm{R}^{1}=\mathrm{H}, \mathrm{R}^{2}=\mathrm{H}, \mathrm{Me}$;

$\mathrm{R}^{3}=\mathrm{H}, \mathrm{Ph} ; \mathrm{R}^{4}=\mathrm{Ph}, \mathrm{Ar},(\mathrm{Me})_{2}$

$\mathrm{X}=\mathrm{C}\left(\mathrm{CO}_{2} \mathrm{R}\right)_{2}, \mathrm{C}\left(\mathrm{SO}_{2} \mathrm{Ph}\right)_{2}, \mathrm{O}$

Conditions $\mathrm{B}$ :

$\mathrm{L}_{\mathrm{q}}-\mathrm{Au}(\mathrm{I}) / \mathrm{AgSbF}_{6}(5 \mathrm{~mol} \%)$

DCE, $25^{\circ} \mathrm{C}, 24 \mathrm{~h}$

27 examples, $40-90 \%, \mathbf{5 1} \mathbf{a} / \mathbf{5 1} \mathbf{b}=>99 / 1$

dr 9:1- >99:1

$2-66 \%$ ee

$\mathrm{R}^{1}=\mathrm{H}, \mathrm{Br} ; \mathrm{R}^{2}=\mathrm{Me}, \mathrm{Bn}, \mathrm{Boc}$;

$\mathrm{R}^{3}=\mathrm{H}, \mathrm{Me} ; \mathrm{R}^{4}=\mathrm{Ar}$

$\mathrm{X}=\mathrm{NBs}, \mathrm{NNs}, \mathrm{NTs}, \mathrm{NSO}_{2} \mathrm{Ar}$

Scheme 17. Cycloisomerizations of enynes in the presence of indoles.
Recently, our group reported on the enantioselective cycloisomerization of 2-alkynyl-enones $\mathbf{5 2}$ in the presence of a range of nucleophiles, including indoles $\mathbf{5 3}$ (Scheme 18). ${ }^{87}$ This reaction, initially developed by Larock with $\mathrm{AuCl}_{3}$ as the catalyst, could be performed with newly designed chiral gold phosphoric acid $\mathbf{L}_{\mathbf{s}}$ as the precatalyst, activated in situ by silver carbonate. With this, a range of ketones $\mathbf{5 2}$ and indoles $\mathbf{5 3}$ were used to generate enantioenriched furanes $\mathbf{5 4}$ in excellent yields and enantioselectivities at only $0.2 \mathrm{~mol} \%$ catalyst loading. The key intermediate in the process is the carbocation $\mathbf{l}$, which is stabilized by the chiral phosphate, which hinders one of the sides of the carbocation. In this ligand design, this is the first time the chiral counterion is intramolecularly linked to the cationic gold species. 88,89<smiles>[R]C#CC1=CNCCC1=O</smiles>

52

$\mathrm{R}^{1}=\mathrm{Alk}, \mathrm{Ar}$

$\mathrm{R}^{2}=5-\mathrm{OMe}, 5-\mathrm{Br}, 6-\mathrm{Me}, 2-\mathrm{Me}, \mathrm{N}-\mathrm{Me}$ $\mathrm{n}=0,1,2$
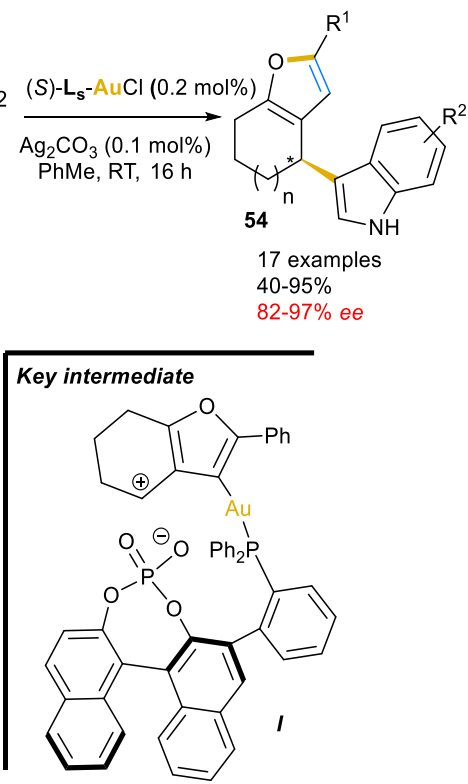

Scheme 18. Cycloisomerization of 2-alkynyl-enones with indoles.

\section{Miscellaneous}

In this brief section, some papers and approaches at the border of the scope of this review are presented, either because the indole is not functionalized or because the gold catalyst is not the source of enantioselectivity in the process.

\subsection{Reaction with the indole being formed in situ}

Gold complexes are not only used to trigger a nucleophilic reaction of the indole but are also able to generate the indole ring in situ from aniline precursors. In the following examples, the indole ring is generated in situ in the course of an enantioselective functionalization, but the indole itself is not further functionalized.

Inspired by previous work on the racemic synthesis of oxazinoindoles starting from the corresponding ortho-alkynylaniline diols, ${ }^{90}$ Bandini's group developed in 2013 the asymmetric methodology to access highly enantioenriched oxazino[4,3$\alpha$ ] indoles $\mathbf{5 6}$ starting from ortho-alkynylaniline allyl diols $\mathbf{5 5}$ and using (S)-DTBM-SEGPHOS $L_{b}$ as the chiral ligand (Scheme 19). ${ }^{91}$ The reaction path goes through the in situ formation of 
intermediate $\boldsymbol{I}$ that further undergoes stereoselective alkoxylation to provide the corresponding products $\mathbf{5 6}$.

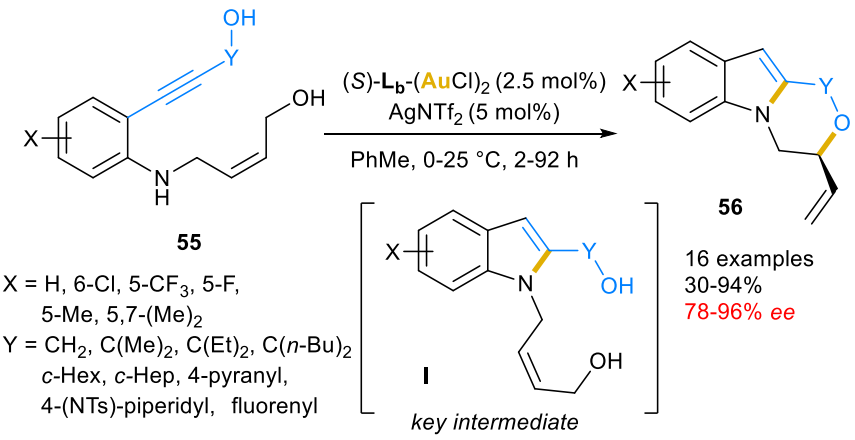

Scheme 19. Access to oxazino-indoles from alkynylaniline-type substrates.

Ohno et al. reported in 2016 the total synthesis of (+)-conolidine using an enantioselective gold-catalyzed formation of the indole ring $\mathbf{5 8}$ combined with the addition of a silyl enol ether to a triple bond $\mathbf{5 7}$ (Scheme 20). ${ }^{92}$ After optimization, they were able to obtain indole $\mathbf{5 8}$ in low to moderated yields but high enantiomeric excess using $(R)$ - DTBM-MeO-BIPHEP $L_{h}$ as the chiral ligand.

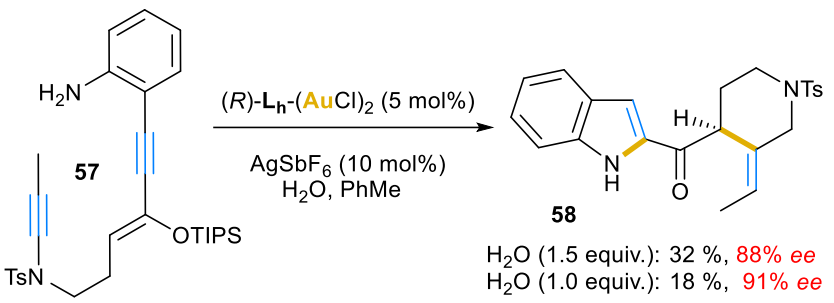

Scheme 20. Formation of functionalized indoles from enyne substrates.

\subsection{Chirality conversion}

Following on Che's report that indoles intermolecularly react with symmetrical allenes, ${ }^{46}$ Lee et al. reported in 2018 an alternative approach using an enantiomerically pure allene $\mathbf{5 9}$ and an achiral gold catalyst, relying on the axial to central chirality conversion (Scheme 21). ${ }^{93,}, 94$ They designed the allenes with an electron-withdrawing group to prevent racemization. They showed that indoles $\mathbf{6 0}$ and these allenes $\mathbf{5 9}$ react to generate compounds $\mathbf{6 1}$ with good regioselectivities (induced by the EWG). Despite the severe loss of the stereochemical information in some cases, conversion percentages (defined as the ee of 61/ee of 59) were high in most examples.

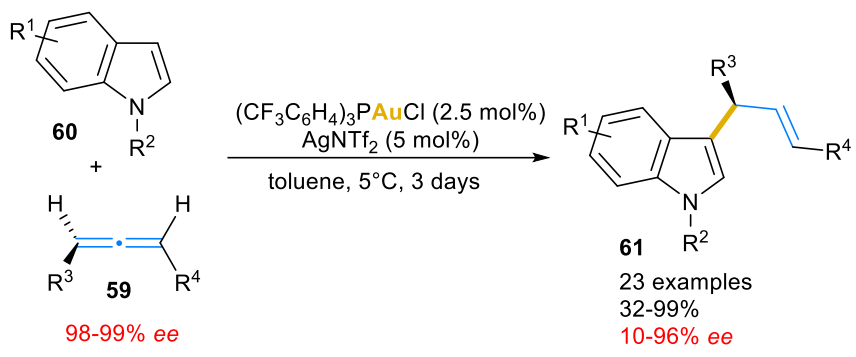

$\mathrm{R}^{1}=\mathrm{H}, \mathrm{F}, \mathrm{Cl}, \mathrm{OMe}, \mathrm{Me}, \mathrm{Et}$

$R^{2}=H, M e, B o c$

$\mathrm{R}^{3}=\mathrm{H}$, Alk

$\mathrm{R}^{4}=\mathrm{NPhth}, \mathrm{CH}_{2} \mathrm{OC}(\mathrm{O}) \mathrm{R}, \mathrm{CH}_{2} \mathrm{OBn}, \mathrm{CH}_{2} \mathrm{CN}, \mathrm{CH}_{2} \mathrm{COOEt},\left(\mathrm{CH}_{2}\right)_{2} \mathrm{NPhth}$,

$\left(\mathrm{CH}_{2}\right)_{2} \mathrm{OBz}, \mathrm{CH}_{2} \mathrm{CH}(\mathrm{COOEt})_{2}$, Ph

Scheme 21. Hydroarylation between indoles and enantiomerically pure allenes.

\section{Conclusions}

Recent progress on the design of chiral gold complexes have lately enabled efficient enantioselective functionalization of indoles by many intramolecular and intermolecular strategies. This review shows the big efforts made by the scientific community to improve ligand design, to extent the scope of given reactivities, but also to better understand the associated mechanisms. Despite these actual progresses, a large number of well-known reactions developed in non enantioselective catalysis are underrepresented or even absent of the bibliographic picture. Firstly, it is clearly visible that intramolecular pathways dominate the literature. Some representative electrophiles have even no -or poorly efficientintermolecular examples so far. For example, enantioselective intermolecular additions of indoles to allenes are scarce, which witnesses the challenge associated to this transformation. On the contrary, reactions involving highly reactive alkynyl-type electrophiles or allenamides are more documented. The linear geometry of gold complexes, making more challenging the sterecontrol of the process, forces to a careful design of the ligand to have excellent enantiocontrol. Here again, it is clear that reaction involving monosubstituted alkynes are highly challenging.

Given the small number of enantioselective processes that have been reported, enantioselective gold-catalysis applied to indole scaffolds has not revealed all its secrets and thus leaves huge horizons opened to the creativity of organic chemists.

\section{Acknowledgments}

Pierre Milcendeau thanks MESRI (Paris-Saclay University) for a PhD fellowship. Nazarii Sabat and Pierre Milcendeau thank the CHARMMMAT Laboratory of Excellence (ANR-11-LABX0039) for financial support.

\section{Notes and references}

1 A. Baeyer, Liebigs Ann., 1866, 140, 295-296.

2 R. J. Sundberg, The chemistry of indoles, Academic Press New York, London, 1970. 
3 S. E. O'Connor and J. J. Maresh, Nat. Prod. Rep., 2006, 23, 532 547.

4 S. Lakhdar, M. Westermaier, F. Terrier, R. Goumont, T. Boubaker, A. R. Ofial and H. Mayr, J. Org. Chem., 2006, 71, 9088-9095.

5 G. Bartoli, G. Bencivenni and R. Dalpozzo, Chem. Soc. Rev., 2010, 39, 4449-4465.

6 R. Dalpozzo, Chem. Soc. Rev., 2015, 44, 742-778.

7 S. Cacchi and G. Fabrizi, Chem. Rev., 2005, 105, 2873-2920.

8 S. Cacchi and G. Fabrizi, Chem. Rev., 2011, 111, PR215-PR283.

9 M. Inman and C. J. Moody, Chem. Sci., 2013, 4, 29-41.

10 M. Bandini and A. Eichholzer, Angew. Chem. Int. Ed., 2009, 48, 9608-9644.

11 J.-B. Chen and Y.-X. Jia, Org. Biomol. Chem., 2017, 15, 3550-3567.

12 A. S. K. Hashmi and G. J. Hutchings, Angew. Chem. Int. Ed., 2006, 45, 7896-7936.

13 A. Fürstner and P. W. Davies, Angew. Chem. Int. Ed., 2007, 46, 3410-3449.

14 N. Krause, V. Belting, C. Deutsch, J. Erdsack, H.-T. Fan, B. Gockel, A. Hoffmann-Roeder, N. Morita and F. Volz, Pure Appl. Chem., 2008, 80, 1063-1069.

15 M. H. Vilhelmsen and A. S. K. Hashmi, in PATAl'S Chemistry of Functional Groups, John Wiley \& Sons, Ltd, 2009, DOI: 10.1002/9780470682531.pat0800.

16 I. Braun, A. M. Asiri and A. S. K. Hashmi, ACS Catal., 2013, 3, 1902 1907.

17 B. Ranieri, I. Escofet and A. M. Echavarren, Org. Biomol. Chem., 2015, 13, 7103-7118.

18 R. A. Widenhoefer, Chem. Eur. J., 2008, 14, 5382-5391.

19 A. S. K. Hashmi, M. Hamzic, F. Rominger and J. W. Bats, Chem. Eur. J., 2009, 15, 13318-13322.

20 S. Sengupta and X. Shi, ChemCatChem, 2010, 2, 609-619.

21 A. Pradal, P. Y. Toullec and V. Michelet, Synthesis, 2011, 15011514.

22 G. Cera and M. Bandini, Isr. J. Chem., 2013, 53, 848-855.

23 W. Zi and D. F. Toste, Chem. Soc. Rev., 2016, 45, 4567-4589.

24 F. Pan, C. Shu and L.-W. Ye, Org. Biomol. Chem., 2016, 14, 94569465.

25 V. Pirovano, Eur. J. Org. Chem., 2018, 2018, 1925-1945.

26 M. Bandini, Chem. Soc. Rev., 2011, 40, 1358-1367.

27 G. Cera, M. Chiarucci, A. Mazzanti, M. Mancinelli and M. Bandini, Org. Lett., 2012, 14, 1350-1353.

28 C. Ferrer and A. M. Echavarren, Angew. Chem. Int. Ed., 2006, 45, 1105-1109.

29 C. Ferrer, C. H. M. Amijs and A. M. Echavarren, Chem. Eur. J., 2007, 13, 1358-1373.

30 M. Jia, G. Cera, D. Perrotta, M. Monari and M. Bandini, Chem. Eur. J., 2014, 20, 9875-9878.

31 V. Magné, F. Blanchard, A. Marinetti, A. Voituriez and X. Guinchard, Adv. Synth. Catal., 2016, 358, 3355 - 3361.

32 V. Magné, P. Retailleau, A. Marinetti, A. Voituriez and X Guinchard, Molbank, 2018, M985.

33 N. Glinsky-Olivier, P. Retailleau and X. Guinchard, Eur. J. Org. Chem., 2018, 5823.

34 W. Xu, W. Wang and X. Wang, Angew. Chem. Int. Ed., 2015, 54, 9546-9549.

35 L. Zhang, Y. Wang, Z.-J. Yao, S. Wang and Z.-X. Yu, J. Am. Chem Soc., 2015, 137, 13290-13300.

36 N. Sabat, F. Soualmia, P. Retailleau, A. Benjdia, O. Berteau and X. Guinchard, Org. Lett., 2020, 22, 4344-4349.

37 V. Magné, A. Marinetti, V. Gandon, A. Voituriez and X. Guinchard, Adv. Synth. Catal., 2017, 359, 4036-4042.

38 P. Aillard, A. Voituriez, D. Dova, S. Cauteruccio, E. Licandro and A. Marinetti, Chem. Eur. J., 2014, 20, 12373-12376.
39 L. Huang, H.-B. Yang, D.-H. Zhang, Z. Zhang, X.-Y. Tang, Q. Xu and M. Shi, Angew. Chem. Int. Ed., 2013, 52, 6767-6771.

40 J.-M. Yang, P.-H. Li, Y. Wei, X.-Y. Tang and M. Shi, Chem Commun., 2016, 52, 346-349.

41 W. Zi, H. Wu and F. D. Toste, J. Am. Chem. Soc., 2015, 137, 32253228.

42 N. Zheng, Y.-Y. Chang, L.-J. Zhang, J.-X. Gong and Z. Yang, Chem. Asian J., 2016, 11, 371-375.

43 J. Matsuoka, H. Kumagai, S. Inuki, S. Oishi and H. Ohno, J. Org. Chem., 2019, 84, 9358-9363.

44 W. Yang and A. S. K. Hashmi, Chem. Soc. Rev., 2014, 43, 29412955.

45 K. L. Toups, G. T. Liu and R. A. Widenhoefer, J. Organomet. Chem., 2009, 694, 571-575

46 M.-Z. Wang, C.-Y. Zhou, Z. Guo, E. L.-M. Wong, M.-K. Wong and C.-M. Che, Chem. Asian J., 2011, 6, 812-824.

47 Z. Zhang, C. Liu, R. E. Kinder, X. Han, H. Qian and R. A. Widenhoefer, J. Am. Chem. Soc., 2006, 128, 9066-9073.

48 C. Liu and R. A. Widenhoefer, Org. Lett., 2007, 9, 1935-1938.

49 Y.-Y. Zhang, Y. Wei and M. Shi, Chem. Commun., 2019, 55, 42104213.

50 Y.-Y. Zhang, Y. Wei and M. Shi, Org. Lett., 2019, 21, 8250-8255.

51 Z. L. Niemeyer, S. Pindi, D. A. Khrakovsky, C. N. Kuzniewski, C. M. Hong, L. A. Joyce, M. S. Sigman and F. D. Toste, J. Am. Chem. Soc., 2017, 139, 12943-12946.

52 L. Zhang, J. Am. Chem. Soc., 2005, 127, 16804-16805.

53 V. Magné, Y. Sanogo, C. S. Demmer, P. Retailleau, A. Marinetti, X. Guinchard and A. Voituriez, ACS Catal., 2020, DOI 10.1021/acscatal.0c01819.

54 P. Aillard, D. Dova, V. Magne, P. Retailleau, S. Cauteruccio, E. Licandro, A. Voituriez and A. Marinetti, Chem. Commun., 2016, 52, 10984-10987.

55 R. Fang, Z. Feng, A. M. Kirillov and L. Yang, Organometallics, 2020, 39, 1782-1789.

56 Z.-Q. Shen, X.-X. Li, J.-W. Shi, B.-L. Chen and Z. Chen, Tetrahedron Lett., 2015, 56, 4080-4083.

57 R. Ocello, A. De Nisi, M. Jia, Q.-Q. Yang, M. Monari, P. Giacinto, A. Bottoni, G. P. Miscione and M. Bandini, Chem. Eur. J., 2015, 21, 18445-18453.

58 M. Jia, M. Monari, Q.-Q. Yang and M. Bandini, Chem. Commun., 2015, 51, 2320-2323.

59 W. Huang, Y.-C. Zhang, R. Jin, B.-L. Chen and Z. Chen, Organometallics, 2018, 37, 3196-3209.

60 V. Pirovano, L. Decataldo, E. Rossi and R. Vicente, Chem. Commun., 2013, 49, 3594-3596.

61 N. Mézailles, L. Ricard and F. Gagosz, Org. Lett., 2005, 7, 41334136.

62 Y. Wang, P. Zhang, Y. Liu, F. Xia and J. Zhang, Chem. Sci., 2015, 6, 5564-5570.

63 V. Pirovano, M. Borri, G. Abbiati, S. Rizzato and E. Rossi, Adv. Synth. Catal., 2017, 359, 1912-1918.

64 V. Pirovano, E. Arpini, M. Dell'Acqua, R. Vicente, G. Abbiati and E. Rossi, Adv. Synth. Catal., 2016, 358, 403-409.

65 Y. Wang, P. Zhang, X. Di, Q. Dai, Z. M. Zhang and J. Zhang, Angew. Chem. Int. Ed., 2017, 56, 15905-15909.

66 N. Glinsky-Olivier and X. Guinchard, Synthesis, 2017, 49, 26052620.

67 R. Dalpozzo, Molecules, 2016, 21, 699.

68 C. Ingallina, I. D'Acquarica, G. Delle Monache, F. Ghirga, D. Quaglio, P. Ghirga, S. Berardozzi, V. Markovic and B. Botta, Curr. Pharm. Des., 2016, 22, 1808-1850.

69 M. Bandini and A. Eichholzer, Angew. Chem. Int. Ed., 2009, 48, 9533-9537. 
70 M. Bandini, A. Gualandi, M. Monari, A. Romaniello, D. Savoia and M. Tragni, J. Organomet. Chem., 2011, 696, 338-347.

71 M. Bandini, A. Bottoni, M. Chiarucci, G. Cera and G. P. Miscione, J. Am. Chem. Soc., 2012, 134, 20690-20700.

72 N. Glinsky-Olivier, S. Yang, P. Retailleau, V. Gandon and X. Guinchard, Org. Lett., 2019, 21, 9446-9451.

73 B. V. Subba Reddy, M. Swain, S. M. Reddy, J. S. Yadav and B. Sridhar, J. Org. Chem., 2012, 77, 11355-11361.

74 S. W. Youn, J. Org. Chem., 2006, 71, 2521-2523.

75 V. Gobé, P. Retailleau and X. Guinchard, Chem. Eur. J., 2015, 21 , 17587-17590.

76 M. Marín-Luna, O. Nieto Faza and C. Silva López, Front. Chem., 2019, 7.

77 Y.-C. Lee and K. Kumar, Isr. J. Chem., 2018, 58, 531-556.

78 A. Marinetti, H. Jullien and A. Voituriez, Chem. Soc. Rev., 2012, 41, 4884-4908.

79 C. H. M. Amijs, C. Ferrer and A. M. Echavarren, Chem. Commun., 2007, 698-700.

80 C. H. M. Amijs, V. López-Carrillo, M. Raducan, P. Pérez-Galán, C. Ferrer and A. M. Echavarren, J. Org. Chem., 2008, 73, 7721-7730.

81 H. Seo, B. P. Roberts, K. A. Abboud, K. M. Merz and S. Hong, Org. Lett., 2010, 12, 4860-4863.

82 P. de Frémont, H. Clavier, V. Rosa, T. Avilés and P. Braunstein, Organometallics, 2011, 30, 2241-2251.

83 C.-M. Chao, M. R. Vitale, P. Y. Toullec, J.-P. Genêt and V. Michelet, Chem. Eur. J., 2009, 15, 1319-1323.

84 A. Pradal, C.-M. Chao, M. R. Vitale, P. Y. Toullec and V. Michelet, Tetrahedron, 2011, 67, 4371-4377.

85 E. S. Andreiadis, M. R. Vitale, N. Mézailles, X. Le Goff, P. Le Floch, P. Y. Toullec and V. Michelet, Dalton Trans., 2010, 39, 10608-10616. 86 J. Yang, R. Zhang, W. Wang, Z. Zhang and M. Shi, Tetrahedron: Asymmetry, 2011, 22, 2029-2038.

87 Z. Zhang, V. Smal, P. Retailleau, A. Voituriez, G. Frison, A. Marinetti and X. Guinchard, J. Am. Chem. Soc., 2020, 142, 3797-3805. 88 S. M. Inamdar, A. Konala and N. T. Patil, Chem. Commun., 2014, 50, 15124-15135.

89 C. C. J. Loh and D. Enders, Chem. Eur. J., 2012, 18, 10212-10225. 90 M. Chiarucci, E. Matteucci, G. Cera, G. Fabrizi and M. Bandini, Chem. Asian J., 2013, 8, 1776-1779.

91 M. Chiarucci, R. Mocci, L.-D. Syntrivanis, G. Cera, A. Mazzanti and M. Bandini, Angew. Chem. Int. Ed., 2013, 52, 10850-10853.

92 S. Naoe, Y. Yoshida, S. Oishi, N. Fujii and H. Ohno, J. Org. Chem., 2016, 81, 5690-5698

93 D. R. Sutherland, L. Kinsman, S. M. Angiolini, G. M. Rosair and A. L. Lee, Chem. Eur. J., 2018, 24, 7002-7009.

94 For a review dealing on chirality transfer and memory of chirality in gold-catalalyzed processes, see: N. T. Patil, Chem. Asian J., 2012, 7, 2186-2194. 